\title{
The Single Mitochondrion, Fine Structure, and Germination of the Spore of Blastocladiella emersonii
}

\author{
BY E. C. CANTINO, J. S. LOVETT, L. V. LEAK AND J. LYTHGOE \\ Department of Botany and Plant Pathology, Michigan State University, \\ East Lansing, Michigan, and Department of Biological Sciences, \\ Purdue University, West Lafayette, Indiana
}

(Received 27 September 1962)

\begin{abstract}
SUMMARY
The motile spore of the water fungus, Blastocladiella emersonii, contains a single, large, posterior, eccentrically disposed mitochondrion; some 6-12 prominent, strongly osmiophilic, lipid-like organelles, bordered by a double membrane, occur along its outer edge. A single flagellum with the classical 9-plus-2 fibrillar structure is attached by at least one banded rootlet to the mitochondrion. The nuclear cap (a package of ribosomes) overlies the nucleus and is separated from it by a double membrane. The cytoplasm is somewhat granular, contains structures believed to be organelles (previously described as $\gamma$ particles), but is devoid of any obvious cytoplasmic reticulum. Before spore germination, the flagellum undergoes a series of characteristic movements. Following this, the nuclear apparatus rotates through some $270^{\circ}$, but the spore itself does not turn. The flagellum is then retracted into the cell. Subsequently, the spore germinates by formation of a germ tube and the nuclear cap disintegrates.
\end{abstract}

\section{INTRODUCTION}

The motile, posteriorly uniflagellate, uninucleate spore of the water mould, Blastocladiella emersonii, is about $7 \times 9 \mu$; the flagellum is about $20 \mu$ long. It was described (Cantino \& Hyatt, 1953; Cantino \& Horenstein, 1956) as possessing: (a) a typically Blastocladiaceous (Sparrow, 1960), crescent-shaped nuclear cap (the so-called 'food body') intimately in contact with and partially covering the nucleus; (b) a large, posteriorly placed, irregularly shaped 'side body' bearing about half a dozen lipid-like granules, the side body being inserted to the side of the nuclear apparatus and near the point of entry of the flagellum; and (c) small organelles labelled $\gamma$ particles, about $0 \cdot 5 \mu$ in diameter and randomly distributed in the cytoplasm with a frequency of about 13 per spore (when derived from 'ordinary colourless' or OC cells). It was shown, finally, that the flagellum was not simply shed or somehow lost, but actually retracted prior to germination of the spore.

The 'side body' has been found in spores of other species of Blastocladiella (Sparrow, 1960). Stüben (1939) reported its presence (his 'Seitenkörper') in a Blastocladiella-like organism, and the occurrence of this organelle was used as a partial basis for creating a new genus, Sphaerocladia. Later, Couch \& Whiffen (1942) showed that such 'side bodies' $(a)$ were demonstrable in osmic-fixed spores of several species of Blastocladiella (for this and other reasons, Stüben's Sphaerocladia was transferred to the genus Blastocladiella); (b) often possessed attached fat-like bodies ; 
and $(c)$ in some instances appeared to be intimately associated with the 'cilium' (flagellum) of the spore.

In this report, we shall show that in Blastocladiella emersonii the 'side body' is a single mitochondrion with which the flagellum is intimately associated, that relative to cell volume it is a giant one, and that no other mitochondria are detectable in the spore.

\section{METHODS}

\section{Preparation of spores}

Single generation populations of OC cells were grown on Petri plates of PYG agar (0.125 \% peptone, $0 \cdot 125 \%$ yeast extract, $0.3 \%$ glucose, and $2.0 \%$ agar; Difco Laboratories, Detroit, Michigan). As soon as discharge of spores began in situ (the exact time depending upon temperature and population density; see Results), plates were flooded with distilled water to accelerate spore liberation (for general procedures and discussion, see McCurdy \& Cantino, 1960; Cantino \& Lovett, 1963). Such suspensions of swimming spores were either used directly for light microscopy or centrifuged for electron microscopy, for which exceptionally dense spore populations were needed and obtained as follows: a Petri plate of mature plants was flooded with about $20 \mathrm{ml}$. of water; the spore suspension thus obtained was used to flood a second plate of Blastocladiella emersonii; the new spore suspension, now much denser, was used to flood a third plate of the fungus, and so on until an adequate concentration was obtained.

\section{Light microscopy}

The flagellum, the nuclear cap, and the prominent refractile granules adjacent to the side body were always clearly distinguishable in unstained spores. When desired, additional eontrast was obtained with a vital stain (Trypan blue, up to $1 \%$ solution) and a filter with maximum transmission at $580 \mathrm{~m} \mu$. Spore suspensions were either examined directly in hanging drop mounts, or mounted (alive) in thin agar blocks as follows:

A drop of a thick spore suspension was preheated to $40^{\circ}$ and added to a drop of molten PYG agar, also at $40^{\circ}$; the two were vigorously mixed and then promptly transferred on to a flat sheet of glass at room temperature, where the suspension solidified into a thin layer immediately. A block with the desired dimensions was cut out, placed on to a coverslip, inverted over a depression slide, and sealed with silicone grease.

\section{Electron microscopy}

For examination of flagellated spores, thick suspensions were centrifuged at about $1800 \mathrm{~g}$ for one min. in $50 \mathrm{ml}$. conical tubes, the supernatant was removed immediately, fixative was added to the loose pellet, and the mixture was shaken vigorously. Pellets were fixed in Zetterqvist's fixative (Pease, 1960) at pH 5.6 and 7.5. Some were fixed first in Zetterqvist's fixative (2-12 hr.) and then in a solution containing $2.5 \% \mathrm{KMnO}_{4}$ and $2.9 \% \mathrm{NaCl}\left(2-12 \mathrm{hr}\right.$.); others were fixed only in the $\mathrm{KMnO}_{4}-\mathrm{NaCl}$ reagent. Time of fixation ranged from $2 \mathrm{hr}$. to $24 \mathrm{hr}$., the latter yielding better results. After fixation, pellets were washed and then dehydrated in 30,60, 80, 95\%, and absolute ethanol, 15-30 min. in each, for methacrylate embedding. Material fixed in $\mathrm{KMnO}_{4}$ was stained with $2 \%$ phosphotungstic acid in absolute ethanol. When pellets were 
to be embedded in vestopal- $W$, they were dehydrated with acetone and then treated according to Ryter \& Kellenberger (1958) and Zellickson \& Hartmann (1960). For embeddings in epon and araldite, spores were processed according to Luft (1961) and Glauert \& Glauert (1958).

For examination of spores which had retracted their flagella, pellets were prepared as above and then allowed to remain at about $25^{\circ}$ for 5 min. before addition of fixative; during this time about half of the spores retracted flagella. An alternative approach made use of thick spore suspensions in solidified agar blocks as employed for light microscopy; these were cut into small pieces at least $1 \mathrm{~mm}$. thick and fixed after different time intervals up to $10 \mathrm{~min}$., but such specimens were not as well preserved as those obtained from pellets.

Sections were made with a diamond knife (Fernandez-Moran, 1956) and glass knives on a Leitz ultra-microtome, mounted on 100- and 200-mesh copper grids covered with a parlodion film, and coated with a thin film of carbon (Pease, 1960). Sections were stained in uranyl acetate or lead hydroxide (Watson, 1958; Dalton \& Zeigel, 1960) and observed with a Phillips $100 \mathrm{~B}$ electron microscope.

Thick sections $(3-5 \mu)$ were cut adjacent to the thin ones $(25-45 \mathrm{~m} \mu)$ and examined with a phase contrast microscope, in order to determine the exact orientation of the section through the spores.

\section{RESULTS}

\section{Optimal conditions for preparation of spore suspensions from $\mathrm{OC}$ cells}

Blastocladiella emersonii produces four kinds of plants, distinguishable from one another by their morphology, colour, and rates of growth (Cantino \& Hyatt, 1953; Cantino, 1961). At maturity, each type of thallus liberates motile uniflagellate

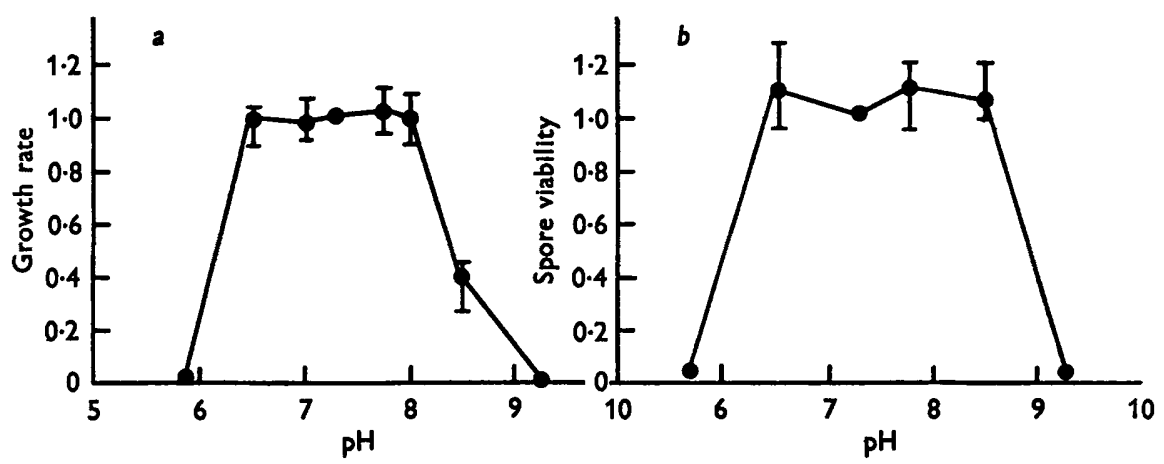

Fig. 1. $a$, The relative growth rate of $\mathrm{OC}$ cells at $20^{\circ}$ on PYG medium adjusted to different $\mathrm{pH}$ levels. Length and width of several dozen randomly selected cells were measured at intervals from about 5 to $18 \mathrm{hr}$; the average increase in size per hour at pH $7 \cdot 3$ was set at 1.0 , and the data obtained at other $\mathrm{pH}$ levels were related to it. $b$, The relative viability of spores (derived from $O C$ cells) on medium PYG at the different $\mathrm{pH}$ values used above. The total number of $\mathrm{OC}$ cells produced from these spores at $\mathrm{pH} 7 \cdot 3$ was set at $1 \cdot 0$, and the number of $\mathrm{OC}$ cells derived from an equal quantity of spores inoculated on PYG at the other pH levels were related to it.

spores and these, too, may differ from one another in viability, size, colour, and the number of certain cytoplasmic organelles (Cantino \& Horenstein, 1956). It was essential to do electron microscopy with homogeneous populations of only one kind 
of swarmer at a time; some of the conditions necessary to achieve this are described below. On solid media, growth of $B$. emersonii is roughly the same between pH 6 and 8 (Fig. 1a). Populations of first generation thalli consist almost wholly of OC cells; RS ('resistant sporangial') cells are not produced, while the appearance of 'orange' and 'late-colourless' cells is delayed until almost all OC cells have reached maturity (Cantino \& Hyatt, 1953). By flooding populations with water when OC cells are ready to discharge swarmers, selection of one class of spores is almost automatically assured. It was also desirable to select conditions where spores exhibit maximum viability and therefore, presumably, maximum uniformity of internal structure. Spore viability (Fig. $1 b$ ) more or less parallels the growth responses



Fig. 2. The effect of temperature on the rate at which a population of $\mathrm{OC}$ cells (about 1000/plate) discharges spores in situ when grown on PYG medium, pH 6.8. Cumulative data are plotted on the vertical axis.

of the parent cells (Fig. 1 a). Consequently, medium PYG at pH 6.8 was selected for growth of OC cells used in electron microscopy. Finally, the rate at which spores were discharged from individual thalli in a population of about $1000 \mathrm{OC}$ cells per Petri plate was established at $20^{\circ}, 22^{\circ}, 24^{\circ}$, and $27^{\circ}$. At $20^{\circ}$ (Fig. 2), $\mathrm{OC}$ cells begin to release their spores at $20 \mathrm{hr}$.; some $4 \mathrm{hr}$. later about $85 \%$ of the population has discharged. At $27^{\circ}$, on the other hand, the process begins at about $15 \mathrm{hr}$. and accordingly it ends earlier. With this information, it is possible to arrange combinations of temperature and time so that cultures can be started and harvested at convenient intervals.

Fine structure of the flagellated spore

Our interpretation of the essential features and fine structures of the spore, as deduced by electron microscopy, is illustrated in Fig. 3. Micrographs which 
illustrate many of these things are shown in the plates and will be referred to in their appropriate places below.

The nuclear cap (Pl. 1, fig. 1) is a striking feature of the spore. As in Allomyces (Turian \& Kellenberger, 1956; Blondel \& Turian, 1960), the cap in Blastocladiella is a massive, granular structure which partially encloses the anterior end of the nucleus. Recently, such nuclear caps were isolated (Lovett, to be published) essentially free from nuclei and nucleoli, and in sufficient quantity to permit quantitative analyses; the data revealed that this organelle consists of ribonucleoprotein particles -presumably, ribosomes. Their possible origin in the developing cell has been discussed elsewhere (Cantino \& Lovett, 1963). The nucleus extends into the nuclear cap

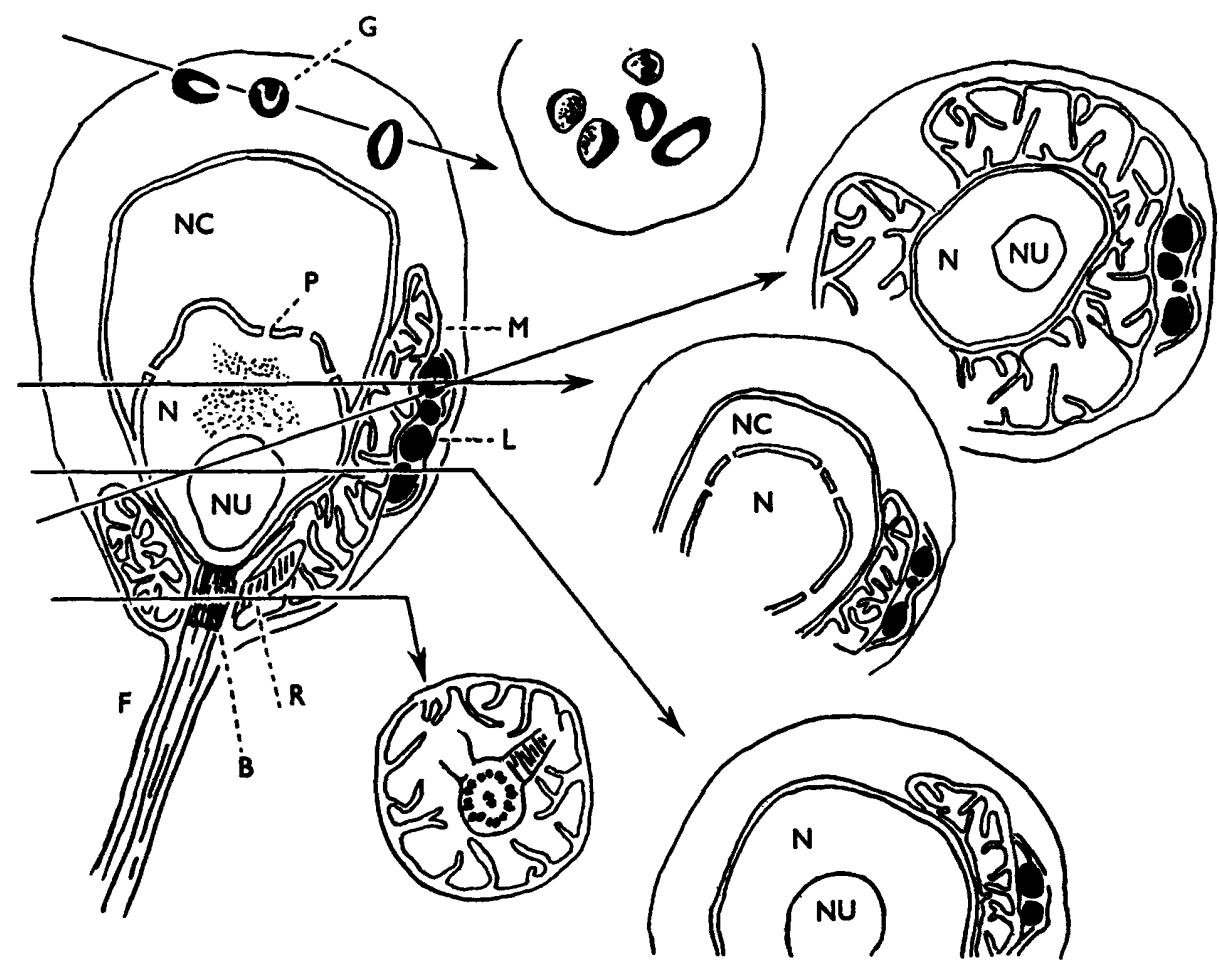

Fig. 3. Interpretive sketch of the details and fine structure of a spore derived from an $\mathrm{OC}$ cell (G, $\gamma$ particle; $N C$, nuclear cap; $N$, nucleus; $N U$, nucleolus; $M$, mitochondrion; L, lipid body; F, flagellum; P, pore; B, basal structure; $R$, banded rootlet).

(Pl. 1, fig. 1; Pl. 3, fig. 6). The cap is separated from the nucleus by a double membrane, which contains round pits of about $1000 \AA$. diameter; these are visible in both cross-section and tangential section on Pl. 2, fig. 2. A cross-section through the top of a nucleus ( $\mathrm{Pl} .2$, fig. 3) reveals how numerous the pores may be in certain areas. These holes are similar in dimension to those described for Allomyces (about 950 A. diameter; Turian \& Kellenberger, 1956). A certain amount of granular material is apparently distributed unevenly in the nucleus, and a nucleolus is embedded in it near the posterior end of the spore (Pl. 1, fig. 1). 


\section{The single mitochondrion of the spore}

In Blastocladiella emersonii, there is a single mitochondrion which, aside from its enormous size (PIs. 1 and 3 ) relative to cell volume, possesses a classical structure with numerous cristae arising by invagination of the inner component of a double membrane (Pl. 4). Without question, it corresponds to the 'side body' seen in the past with the light microscope. This situation contrasts markedly with that described for motile cells - albeit gametes - of Allomyces, wherein many small mitochondria occur (Turian \& Kellenberger, 1956). In B. emersonii, the mitochondrion completely surrounds the base of the flagellum (Pls. 4; Pl. 6, fig. 13); it extends upward along one side almost to the anterior end of the nuclear apparatus, while on the opposite side it extends upward for a short distance only (Pl. 1, fig. 1; Pl. 3, fig. 4). Fibres of the flagellum enter the spore through a central opening in the mitochondrion (Pls. 1 and 4). Extending from this cavity, there is at least one lateral canal-and a second one is often visible (Pls. 4 and 5)-which may be lobed (Pl. 6, fig. 14) and which penetrates for some distance through the body of the mitochondrion. Whenever a banded structure has been detected, it has always been found in such a canal (see later).

The refractive granules, seen by light microscopy to be associated loosely with the 'side body', are immediately evident in electron micrographs (Pl. 3, fig. 5). They lie in one to several layers, number roughly 6-12, and are intimately adjacent to the mitochondrion but clearly separated from the cytoplasm by a double membrane. Judging from their refractiveness in the light microscope and their strongly osmiophilic character in the electron microscope, they are in all probability lipoidal bodies.

\section{The flagellum and its point of attachment}

The flagellum contains 9 outer and 2 inner fibres, each of them a double structure (Pl. 6, fig. 15), and is attached to the posterior end of the spore. The flagellar sheath is confluent (Pl. 1, fig. 1 ) with the outer membrane of the cell, while the fibres end abruptly at the nuclear membrane (Pl. 1, fig. 1). At this point, the aggregate of fibres is clearly differentiated into a sort of basal structure (Pl. 3, fig. 4 ; Pl. 5, fig. 10) which appears to be anchored by non-banded, rootlet-like appendages extending upward between the nucleus and the mitochondrion (Pl. 5, fig. 9). A second structure which also originates near the base of the flagellum appears quite regularly; whether it is an individual fibre or consists of 2 or more fibrils is not yet clear. It lies in a lateral canal in the mitochondrion and consists of a series of transverse, electrondense plates with an average diameter of $210 \AA$. (Pl. 5, fig. 10; Pl. 6, figs. 11, 12); presumably, it is a 'rootlet' (see Discussion). We have never seen more than one of these stranded structures in any single picture, although two lateral canals in the mitochondrion (Pl. 4, fig. 7; Pl. 6, figs. 11, 14) are frequently visible simultaneously. In every instance where we have seen it, the 'rootlet' extends only into the long arm of the mitochondrion.

\section{The cytoplasm and inclusions}

The cytoplasm, although somewhat granular, is conspicuously devoid of an obvious endoplasmic reticulum. The only well defined inclusions in Blastocladiella 
are some strongly osmiophilic organelles bound by a single membrane (Pl. 6, fig. 16); clearly, these should not be confused with the lobed osmiophilic granules of different shape found in the cytoplasm of Allomyces (Blondel \& Turian, 1960). We believe that they consist of a spherical body incompletely girdled by a band of strongly osmiophilic material.

\section{Retraction of the flagellum}

When viewed in the light microscope, motile spores of Blastocladiella emersonii are similar in most respects to those figured by Couch \& Whiffen (1942) for B. simplex; however, they do not possess any detectable structure which would clearly correspond to a rhizoplast (unless the basal structure at the flagellar terminus is
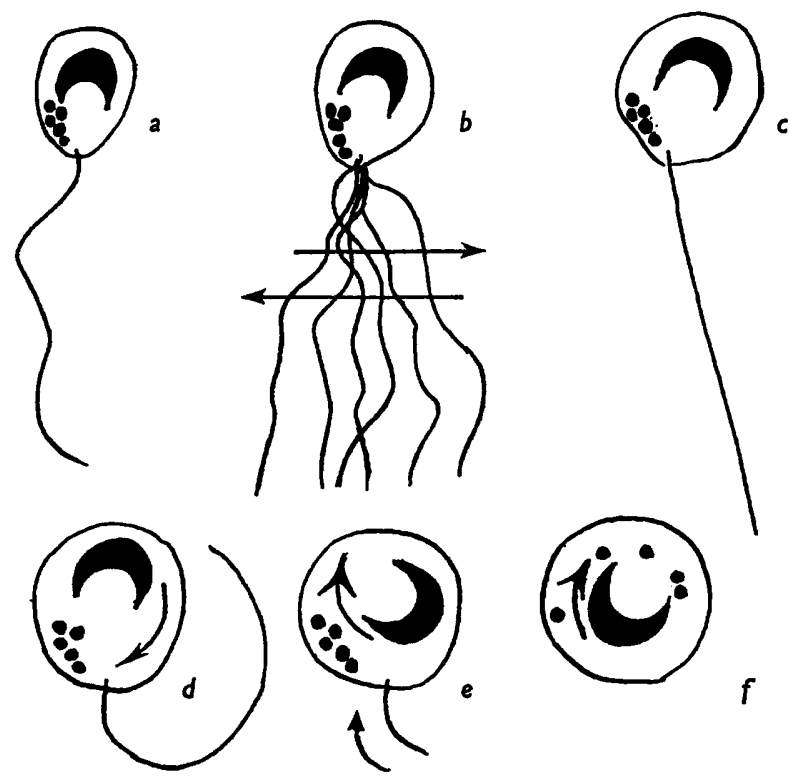

Fig. 4. The sequence of events involved in retraction of the flagellum by a spore from an OC cell (see text).

likened to one). In its active swimming state, the spore is roughly ovoid and is propelled by a whiplash flagellum in which the terminal region tapers gradually (Cantino \& Hyatt, 1953). Often, the spore stops swimming and begins to move about in amoeboid fashion, only to begin swimming once again at a later time; the flagellum is never lost under these conditions. In hanging drop mounts, the time at which the spore rounds up and finally retracts its flagellum depends upon environmental conditions; at $25^{\circ}$, it commonly occurs about $30 \mathrm{~min}$. after cultures are set up.

The first indication that retraction of the flagellum may begin occurs when it stops its propulsive whiplash beat (Fig. 4a) and, instead, begins to vibrate rapidly back and forth (Fig. 4b). This type of fibrillation, which lasts for some 5-10 sec., apparently has no propulsive force, because the cell settles down and then remains 
quite stationary. When this activity has ceased, the spore does one of two things; either it resumes its active whip-lash beat (Fig. $4 a$ ), or its flagellum becomes very still for about $5 \mathrm{sec}$. (Fig. 4c). After the latter has occurred, the spore either moves about slowly in amoeboid fashion for a while and then goes through the cycle shown in Fig. 4a-c, or it immediately begins retracting its flagellum as follows: following the stage shown in Fig. 4c, the cell becomes irregularly spherical. The flagellum sweeps around in a wide arc, and then it becomes stationary once more (Fig. $4 d$ ). At this stage the nuclear apparatus (as reflected by the position of the cap) begins to turn within the cell in a direction opposite to that taken by the flagellum; generally, it rotates through about $270^{\circ}$ (Fig. 4e). Simultaneously, the flagellum gets shorter and quickly vanishes, apparently within the body of the cell; however, the flagellum has never been seen inside the cell. During this whole process, which takes some 30-40 sec. (Fig. 4d-f), the spore itself does not rotate. While the nuclear apparatus is turning, the disposition of the refractive granules attached to the 'side body'that is, the mitochondrion-does not change. But, when the nuclear cap has nearly completed its turn, the constellation of granules does become disorganized; the granules rearrange themselves in a more-or-less curved line throughout the spore body (Fig. $4 f$ ). Simultaneously, the cell, which was irregularly spherical at the beginning of retraction, now becomes an almost perfect sphere; it remains this way until a rhizoid is produced some $\mathbf{1 0 - 3 0}$ min. later.

When spores are embedded in agar rather than suspended freely in hanging drops, flagellar retraction becomes more closely synchronized; it begins by about the 2nd min. after embedding and is completed by the 5th. Under these conditions, the spore rounds up by the time it is examined microscopically, and the viscosity of the system tends to interfere with flagellar movements (as in Fig. 4c, d). Retraction does occur, however, and each spore subsequently produces a germling.

\section{Spore structure after flagellar retraction}

Attempts were made to ascertain with both light and electron microscopy what happened to the flagellum upon retraction. All that can be said with certainty is that no trace of the 9-plus-2 flagellar structure was ever found. But, some $20 \mathrm{hr}$. later, when a germinating spore has given rise to a new thallus, hundreds of secondgeneration spores are cleaved out again from the multinucleate protoplast within the plant (Pl. 7, fig. 17); each of these, upon discharge, possesses a new flagellum and the cycle begins anew.

\section{DISCUSSION}

Fine structure

Cytological investigations, notably those of Cotner (1930), Matthews (1987), Couch \& Whiffen (1942), and Koch (1961) have been made on spores of aquatic fungi, but early workers were handicapped by the inadequate resolution of the light microscope. Turian \& Kellenberger (1956) and Blondel \& Turian (1958) made the first, detailed electron-microscopic studies of the fine structure of motile cells in the water mould Allomyces.

The present investigation of fine structure in the spore of Blastocladiella emersonii reveals an anatomy similar to that reported for Allomyces but by no means identical with it. The similarity lies in the structure and mutual disposition of the nucleus, 
nucleolus, and nuclear cap. Turian (1956) showed cytochemically that the cap in Allomyces appears to contain RNA; Lovett's (to be published) chemical analyses of isolated caps in $B$. emersonii reveal that this organelle is, indeed, a tightly packed aggregate of ribosomes. There are, however, three main points of difference between these two fungi:

(1) There are many mitochondria distributed throughout the body of the motile gamete of Allomyces (no report is available on its spores); in the spore of Blastocladiella there is only one, very large, eccentrically oriented mitochondrion, which surrounds the basal part of the flagellum. We do not know of any comparable structure described in other fungi. Perhaps the nearest thing to it is the way in which mitochondria surround the tail in sperm cells; for example, the arrangement of four large mitochondria around the flagellar base in the Oyster (Galstoff \& Philpott, 1960), and in the annelid worm Hydroides (Colwin \& Colwin, 1961).

(2) The small cytoplasmic organelles (Fig. 3) in Blastocladiella are different from those in Allomyces. Since it is unlikely that the difference in shape resulted from variations in technique, we conclude that this distinction is real. Furthermore, since no other clear-cut cytoplasmic particles are present, these organelles are almost certainly the $\gamma$ particles seen with the light microscope (Cantino \& Horenstein, 1956) and implicated in the development of B. emersonii (Cantino \& Horenstein, 1954).

(3) The banded apparatus (Fig. 3) associated with the basal part of the flagellum in Blastocladiella does not occur, apparently, in Allomyces; indeed, it does not appear to be quite the same as some of the fibrous structures found in comparable locations within other organisms. For example, bands have not been found in the flagellum roots of Euglena (Gibbs, 1960), the rootlet fibres in the zoospore of a brown alga (Manton, 1957), nor the rootlet fibres of the ciliate, Nyctotherus (King et al. 1961). In other instances, however, bands occur, i.e. in the fused double rootlet fibres of Pleurobrachia (Bradfield, 1955), the anterior fibrilla of Colpidium (Pitelka, 1961), and especially the rootlet fibres illustrated by Fawcett \& Porter (1954) for the ciliated epithelium of a frog and a mollusc. It is tempting to consider the latter and the rootlets of $B$. emersonii as homologous structures.

In Blastocladiella, the banded body extends deeply into a lateral canal in the mitochondrion; indeed, it appears to be in intimate contact with it. Whether or not the banded structure is consistently separated by a double membrane from the interior of the mitochondrion has not been decided. Photographic evidence for the connexion between the basal region of the flagellum and a mitochondrion in Oyster sperm (Galstoff \& Philpott, 1960) demonstrates that such a situation is not impossible; pictures of the sperm of Hydroides (Colwin \& Colwin, 1961) and the protozoon Leishmania (Pyne, 1958) suggest the same thing.

\section{Flagellar retraction}

A beginning has been made in answering a central question: what is the mechanism of flagellar retraction in Blastocladiella emersonii? Observations with the light microscope revealed two things: $(a)$ that an intriguing sequence of events is associated with movement of the tail; and in particular $(b)$ that, in the brief interval during which the flagellum is retracted, the nuclear apparatus turns through some $270^{\circ}$, while the giant mitochondrion-using its associated lipid granules as markersremains intact and essentially stationary until the flagellum is almost completely 
absorbed. Only during the very last stage of retraction does the 'side body' appear to begin to change in aspect in that the fat-like granules originally attached to it become distributed throughout the cell. Electron micrographs of cells fixed $5 \mathrm{~min}$. after retraction confirmed that the lipid-like bodies are no longer associated with it. But in no instance has a 9-plus-2 flagellar structure ever been found within such cells; we can only conclude that the flagellum is digested or otherwise dispersed within a few sec. after it enters the cell. Finally, as to mode of entry, we have entertained the thought that rotation of the nuclear apparatus might represent a mechanism for 'winding in' the flagellum, so to speak; however, there is not enough evidence to support or refute this notion.

This work was supported by research grants to E. C. Cantino from the National Institutes of Health, the National Science Foundation, and the Institutional Grants Committee of Michigan State University, and to J. S. Lovett from the National Science Foundation.

\section{REFERENCES}

Blondel, B. \& Turian, G. (1958). Étude sur le champignon Allomyces macrogymus Em. Proc. 4th Int. Conf. Electron Microscopy, p. 507.

Blondel, B. \& Turian, G. (1960). Relation between basophilia and fine structure of cytoplasm in the fungus Allomyces macrogynus Em. J. biophys. biochem. Cytol. 7, 127.

Bradfiedo, J. R. G. (1955). Fibre patterns in animal flagella and cilia. Soc. exp. Biol. 9, 306.

Cantino, E. C. (1961). The relation between biochemical and morphological differentiation in non-filamentous aquatic fungi. Symp. Soc. gen. Microbiol. 11, 243.

Cantino, E. C. \& Horenstern, E. A. (1954). Cytoplasmic exchange without gametic copulation in the water mold Blastocladiella emersonii. Amer. Nat. 88, 143.

Cantino, E. C. \& Horenstein, E. A. (1956). Gamma and the cytoplasmic control of differentiation in Blastocladiella. Mycologia, 48, 443.

Cantino, E. C. \& Hyatr, M. T. (1953). Phenotypic 'sex' determination in the life history of a new species of Blastocladiella, B. emersonii. Leeurwenhoek ned. Tijdschr. 19, 25.

CANTINo, E. C. \& LovetT, J. S. (1963). Non filamentous aquatic fungi; model systems for biochemical studies of morphological differentiation. Advances in Morphogenesis, Vol. 3 (in the Press).

Colwin, A. J. \& Colwin, L. H. (1961). Fine structure of the spermatozoon of Hydroides hexogonus (Annelida) with special reference to the acrosomal region. J. biophys. biochem. Cytol. 10, 211.

CotNer, F. G. (1930). Cytological study of the zoospores of Blastocladia. Bot. Gaz. 89, 295.

Couch, J. N. \& Whrfen, A. J. (1942). Observations on the genus Blastocladiella. Amer. J. Bot. 29, 582.

Dalton, A. J. \& Zeigel, R. F. (1960). A simplified method of staining biological material with lead hydroxide. J. biochem. biophys. Cytol. 7, 409.

FAwCEtT, D. W. \& Porter, K. R. (1954). A study of the fine structure of ciliated epithelia. J. Morphol. 94, 221.

Fernandez-Moran, H. (1956). A new microtome with diamond knife. Industr. Diam. Rev. 16, 128.

Galstoff, P. S. \& Philpott, D. E. (1960). Ultrastructure of the spermatozoon of the oyster Cranostrea virginica. J. ultrastruct. Res. 3, 261.

Gribs, S. P. (1960). The fine structure of Euglena gracilis with special reference to the chloroplasts and pyrenoids. J. ultrastruct. Res. 4, 127.

Glauert, A. M. \& Glauert, R. H. (1958). Araldite as an embedding medium for electron microscopy. J. biochem. biophys. Cytol. 4, 191.

King, R. L., Beams, H. W., Takmisian, T. N. \& Devine, R. L. (1961). The ciliature and ultraciliature of Nyctotherus ovalis. J. Protozool. 8, 98. 


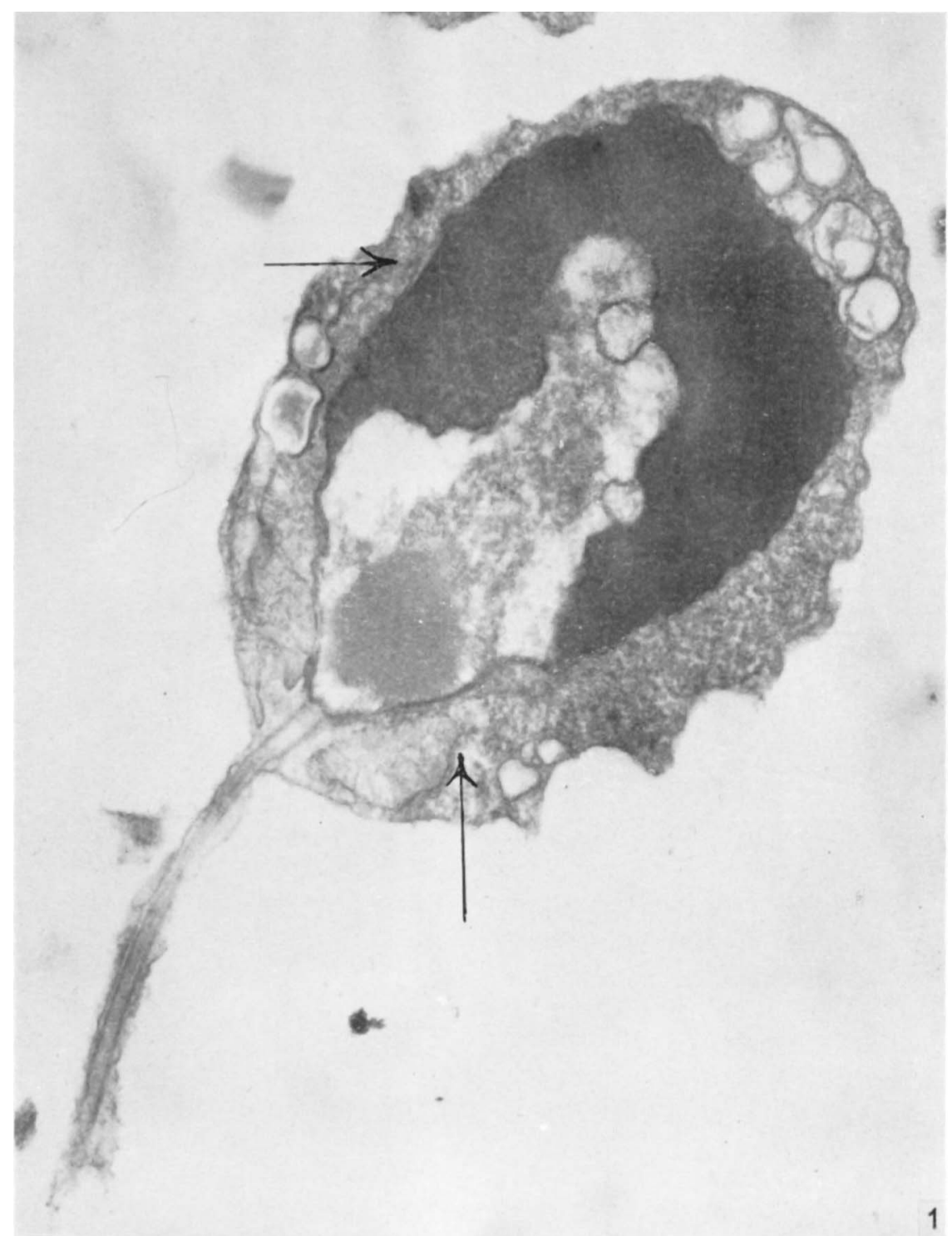



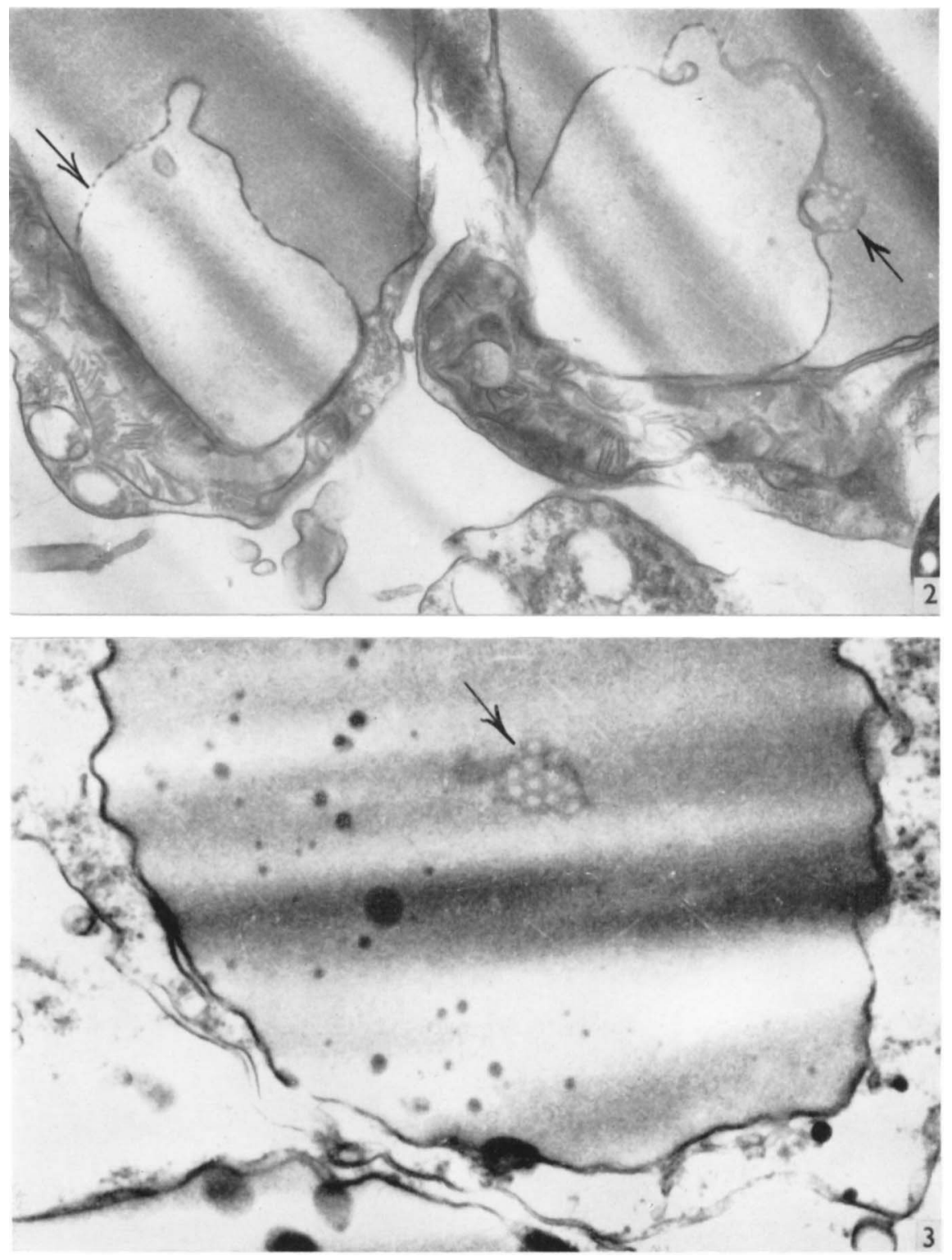

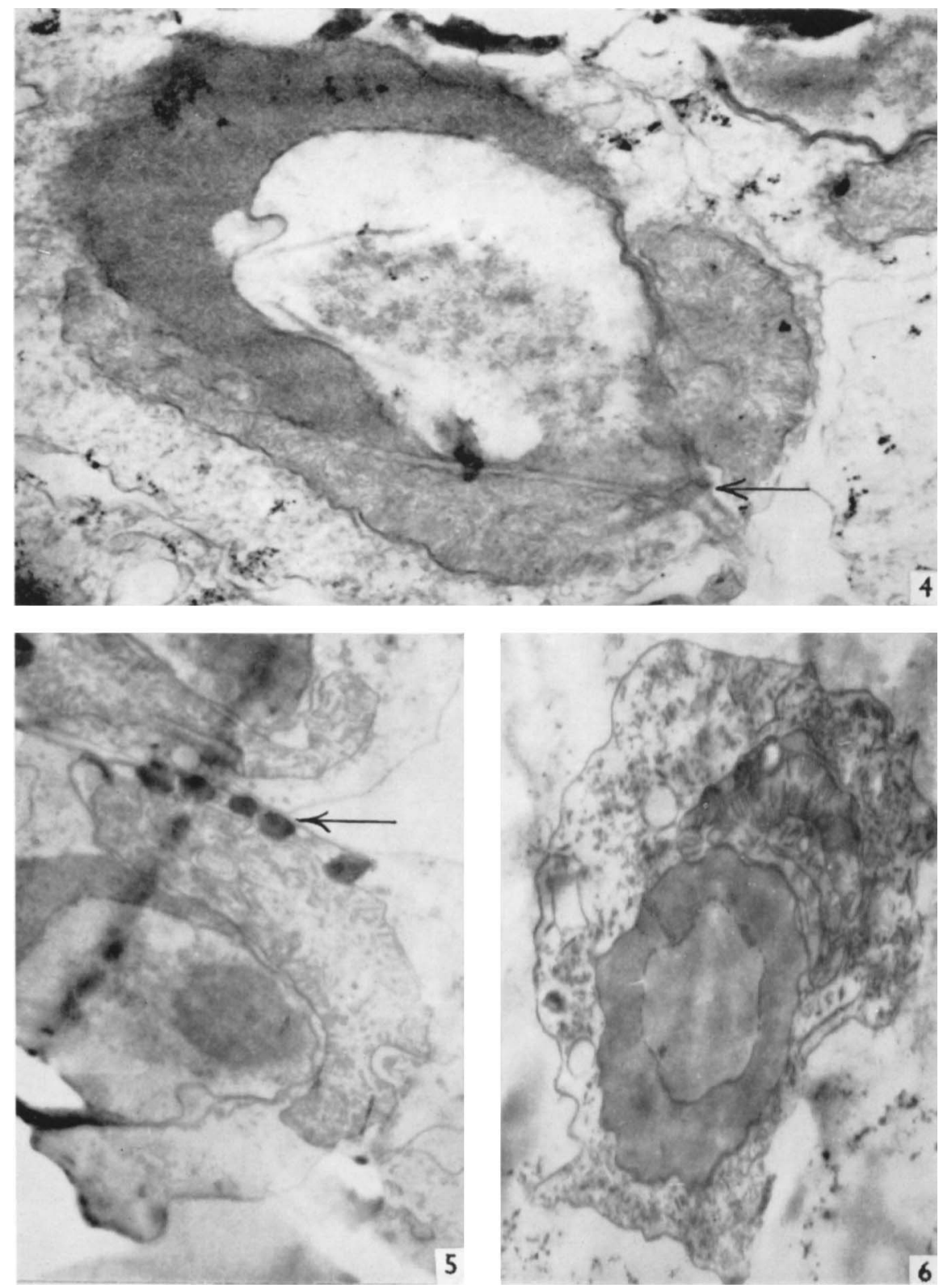

E. C. CANTINO AND OTHERS 

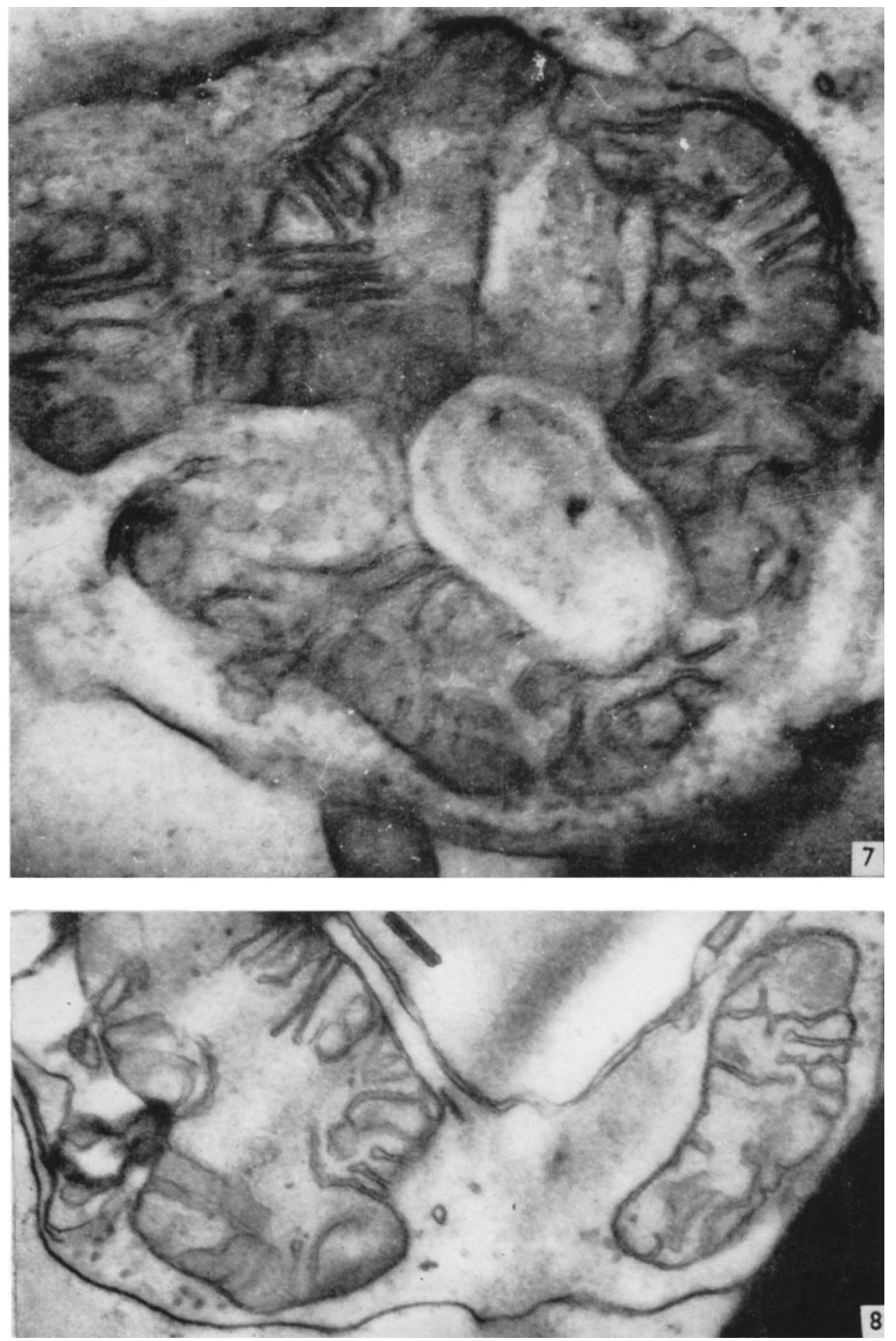

E. C. CANTINO AND OTHERS 

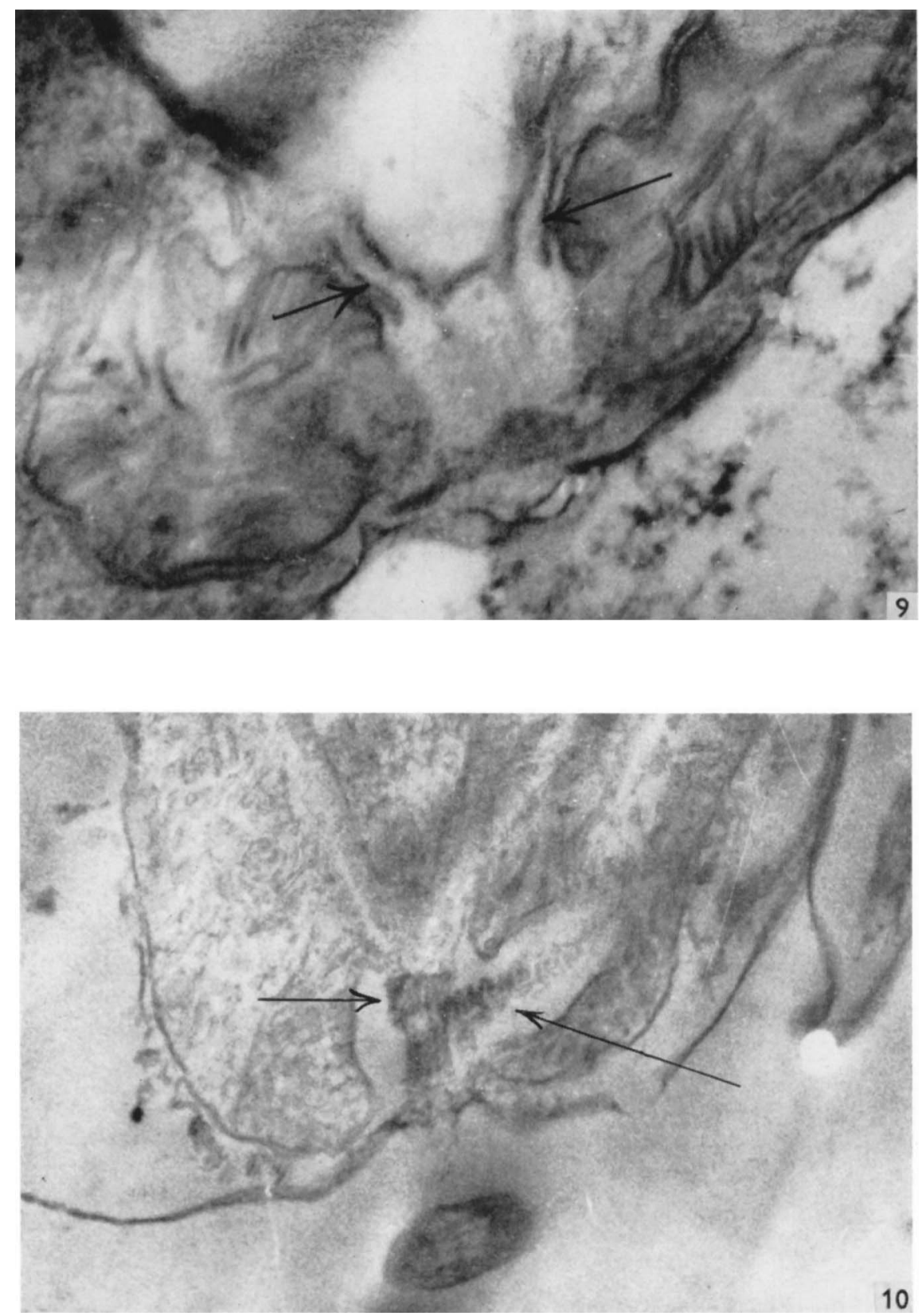

E. C. CANTINO AND OTHERS 

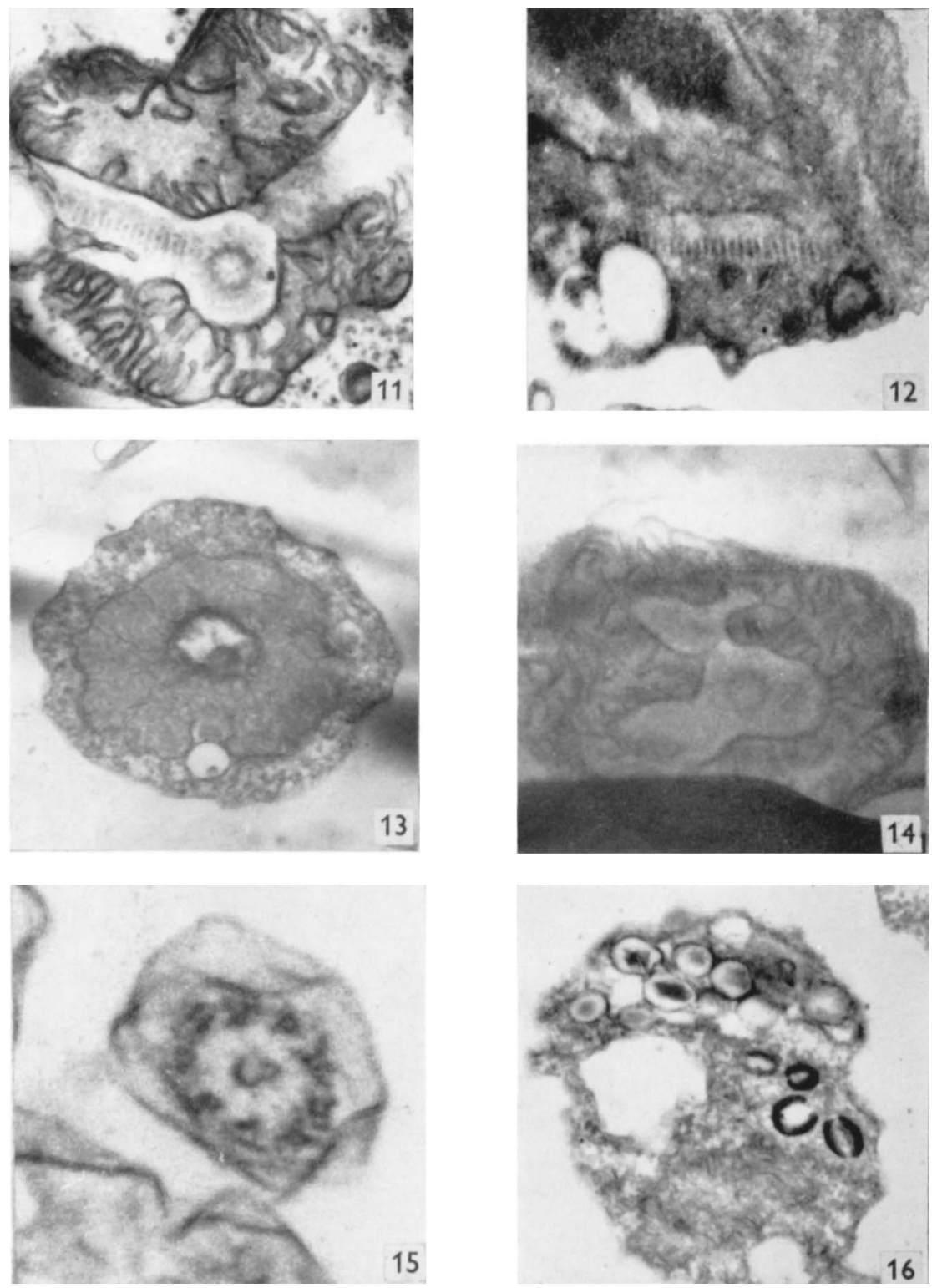

E. C. CANTINO AND OTHERS 
Journal of General Microbiology, Vol. 31, No. 3

Plate 7

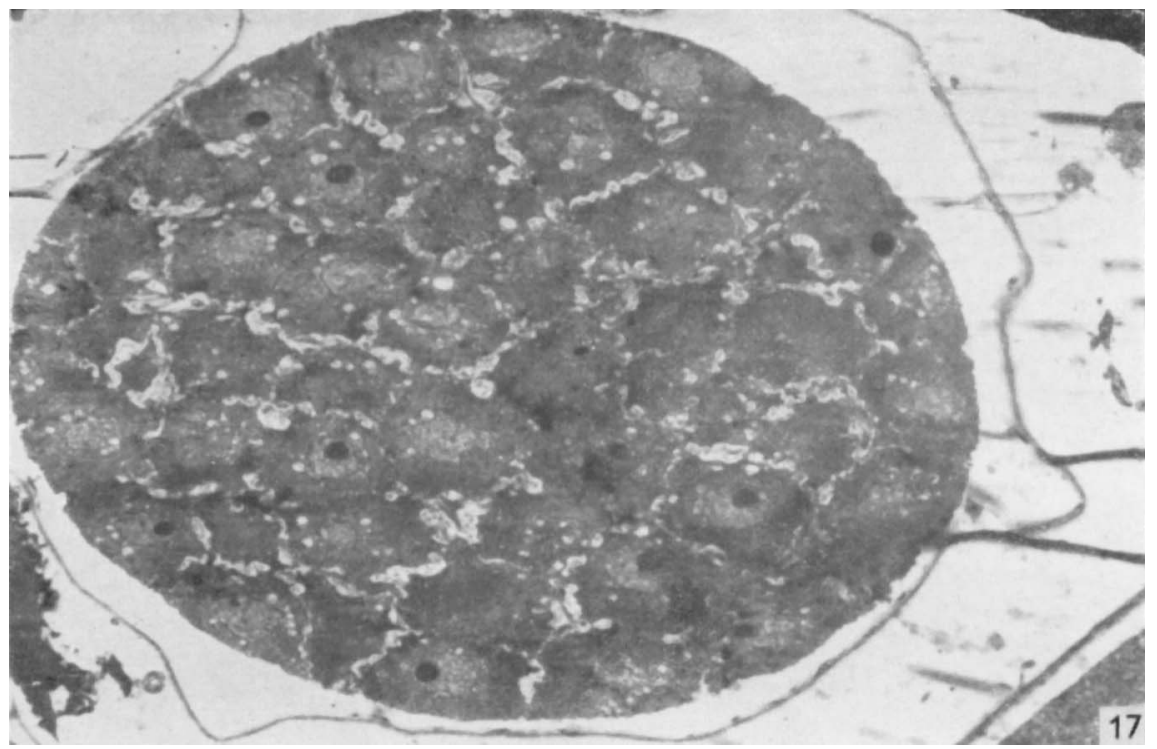

E. C. CANTINO AND OtHeRS 

KocH, W. J. (1961). Studies of the motile cells of chytrids. III. Major types. Amer. J. Bot. 48, 786.

LUFT, J. H. (1961). Improvements in epoxy resin embedding methods. J. biochem. biophys. Cytol. 9, 409.

MANTON, I. (1957). Observations with the electron microscope on the internal structure of the zoospore of a brown alga. J. exp. Bot. 8, 294.

Matrhews, V. D. (1937). A new genus of the Blastocladiaceae. J. Elisha Mitchell Sci. Soc. $53,191$.

McCurdy, H. D., Jun. \& Cantino, E. C. (1960). Isocitritase, glycine-alanine transaminase, and development in Blastocladiella emersonii. Plant Physiol. 35, 463.

Pease, D. C. (1960). Histological Techniques for Electron Microscopy. New York: Academic Press.

Prtelka, D. R. (1961). Fine structure of the silverline and fibrillar systems of three tetrahymenid ciliates. J. Protozool. 8, 75.

Pyne, C. K. (1958). Electron microscope investigations on the leptomonad form of Leishmania donovani. Exp. Cell Res. 14, 388.

RYter, A. \& KELlenberger, E. (1958). L'inclusion au polyester pour l'ultramicrotomie. J. ultrastruct. Res. 2, 200.

Sparrow, F. K., Jun. (1960). Aquatic Phycomycetes. Ann. Arbor, Michigan, U.S.A.: Univ. Mich. Press.

STÜBEN, H. (1939). Über Entwicklungsgeschichte und Ernährungsphysiologie eines neuen niederen Phycomyceten mit Generationswechsel. 'Planta', 30, 353.

TuRIan, G. (1956). Le corps paranucléaire des gamètes géants d'Allomyces javanicus traité à l'acide borique. Protoplasma, 47, 135.

Turian, G. \& Kellenberger, E. (1956). Ultrastructure du corps paranucléaire, des mitochondries et de la membrane nucléaire des gamètes d'Allomyces macrogynus. Exp. Cell Res. 11, 417.

WATson, M. L. (1958). Staining of tissue sections for electron microscopy with heavy metals. II. Application of solutions containing lead and barium. J. biochem. biophys. Cytol. 4, 727.

Zeluickson, A. S. \& Hartmann, J. R. (1960). Vestopal W, a superior embedding medium for electron microscope study of human epidermis. J. invest. Derm. 35, 315.

\section{EXPLANATION OF PLATES}

Plates 1-6. Electron micrographs of thin sections of the spore of Blastocladiella emersonii. Plate 7. Electron micrograph of a section through a mature $O C$ plant of $B$. emersonii undergoing protoplasmic cleavage into spores.

\section{Plate 1}

Fig. 1. Longitudinal section through a spore. The flagellar sheath is continuous with the spore membrane, and a core of flagellar fibres extends through the channel in the mitochondrion and terminates at the nuclear membrane. The single mitochondrion is eccentrically situated in the spore, with its short end at right (arrow) and its long end at left extending upward to a region (arrow) opposite the massive nuclear cap. The nucleus sometimes invaginates into the nuclear cap as seen here, but in other instances it does not do so; whether or not this variability is a property of the spore or an artifact produced in preparation has not been decided. $\times 17,000$. Fixative, Zetterqvist, $\mathrm{pH} 7$, followed by $\mathrm{KMnO}_{4}-\mathrm{NaCl}$.

\section{Pluate 2}

Fig. 2. Section through the nucleus in the basal regions of two spores. At left, the pores in the nuclear membrane (arrow) separating nucleus and nuclear cap are shown in longitudinal section; at right, tangential sections through such pores are seen (arrow). The mitochondrion below the nucleus is particularly obvious once again. $\times 14,200$. Fixative, $\mathrm{KMnO}_{4}-\mathrm{NaCl}$.

Fig. 3. A cross-section through the nuclear cap at a region just below the point where the nucleus makes contact with the cap. Only the tip of the nucleus is visible, and the pores in the membrane (arrow) separating nucleus and nuclear cap are particularly evident. $\times 23,500$. Fixative, $\mathrm{KMnO}_{4}$ $\mathrm{NaCl}$. 
Plate 8

Fig. 4. Longitudinal section through a spore. Note size of the eccentrically placed mitochondrion in relation to nucleus and nuclear cap, and the differentiated region (arrow) of the base of the flagellum. $\times 16,600$. Fixative, Zetterqvist, pH 5 .

Fig. 5. Longitudinal section through basal part of spore showing five of the lipid granules (arrow) always associated with the long end of the mitochondrion and retained by a double membrane. $\times$ 18,000. Fixative, Zetterqvist, $\mathrm{pH} 7$.

Fig. 6. A cross-section through a spore above the region of the nucleolus and the short arm of the mitochondrion, but through the nucleus, nuclear cap, and the long arm of the mitochondrion. Note double membrane around lipid granules. $\times 12,000$. Fixative, KMnO.

\section{Plate 4}

Fig. 7. A cross-section of the mitochondrion at the base of the spore showing the central fiagellar channel and two lateral canals attached thereto. Note extensive cristae. $\times 87,200$. Fixative, $\mathrm{KMnO}_{4}-\mathrm{NaCl}$.

Fig. 8. A longitudinal section through the base of a spore illustrating the structure of the cristae and the central channel through the mitochondrion. $\times 87,200$. Fixative, $\mathrm{KMnO}_{4}-\mathrm{NaCl}$.

\section{Plate 5}

Fig. 8. Longitudinal section through the base of a spore illustrating the non-banded appendages (arrows) extending up along the nucleus, by which the flagellum appears to be partially anchored. $\times \mathbf{8 8 , 5 0 0}$. Fixative, $\mathrm{KMnO}_{\mathbf{4}}-\mathrm{NaCl}$.

Fig. 10. A longitudinal section through the base of a spore showing the differentiated region of the fiagellar structure at the point where it ends adjacent to the nucleus (arrow), and a banded 'rootlet' attached thereto and extending into one of the lateral canals (arrow) in the mitochondrion. $\times 29,500$. Fixative, Zetterqvist, pH 7 .

\section{Plate 6}

Fig. 11. A cross-section through the mitochondrion of the spore showing its central channel, the core of flagellar fibres, the banded rootlet attached thereto extending into the lateral mitochondrial canal (left), and a second lateral canal (right) devoid of a rootlet. $\times 16,700$. Fixative, $\mathrm{KMnO},-\mathrm{NaCl}$.

Fig. 12. A longitudinal section through part of the basal region of the spore illustrating a rootlet with particularly regular bands extending into a lateral canal of the mitochondrion. $\times 17,500$. Fixative, Zetterqvist, pH 7 .

Fig. 18. A cross-section through a spore below the nuclear region showing how the mitochondrion completely surrounds the channel through which the flagellar apparatus enters the cell. $\times 18,600$. Fixative, Zetterqvist, pH 7, followed by $\mathrm{KMnO}_{4}-\mathrm{NaCl}$.

Fig. 14. Cross-section through a mitochondrion at the base of the spore showing the central channel through which the flagellar structure (note ring of fibres) enters the cell, and two lateral canals with one obviously lobed. $\times 18,000$. Fixative, $\mathrm{KMnO}_{-}-\mathrm{NaCl}$.

Fig. 15. Cross-section of a flagellum showing the double nature of the nine outer fibres and the two central ones. $\times 144,000$. Fixative, Zetterqvist, pH 5 .

Fig. 16. Cross-section through a cytoplasmic region of the spore showing the cytoplasmic organelles believed to correspond to $\gamma$ particles. $\times 18,000$. Fixative, Zetterqvist, pH 7 , followed by KMnO,-NaCl.

\section{Plate 7}

Fig. 17. A cross-section through a mature OC plant which has cleaved out its protoplast into spores. The small, dark, spherical structures surrounded by light areas are nucleoli and nuclei, respectively. The spores are separated from one another by intercellular spaces (white irregular lines). Note that the total protoplast of the plant has been used for spore production. $\times 3100$. Fixative, Zetterqvist, pH 7 , followed by $\mathrm{KMnO}_{4}-\mathrm{NaCl}$. 